Christdas \& Pushpanathan | J Pure Appl Microbiol | 14(suppl 1):695-698 | May 2020 Article 6244 | https://doi.org/10.22207/JPAM.14.SPL1.02

Print ISSN: 0973-7510; E-ISSN: 2581-690X

\title{
COVID-19 Prophylaxis: The Desperate Need for
}

\section{Mankind}

\section{Johnson Christdas ${ }^{1 *}$ and Muthuirulan Pushpanathan ${ }^{2 *}$}

${ }^{1}$ Department of Microbiology, The American College, Madurai, India.

${ }^{2}$ Department of Human Evolutionary Biology, Harvard University, Cambridge, MA, USA.

*Correspondence: johnsonchristdas@gmail.com, muthuirulanp@fas.harvard.edu

(Received: April 23, 2020; accepted: April 28 2020)

Citation: Christdas J, Pushpanathan M. COVID-19 Prophylaxis: The Desperate Need for Mankind. J Pure Appl Microbiol. 2020;14(suppl 1):695-698. doi: 10.22207/JPAM.14.SPL1.02

C The Author(s) 2020. Open Access. This article is distributed under the terms of the Creative Commons Attribution 4.0 International License which permits unrestricted use, sharing, distribution, and reproduction in any medium, provided you give appropriate credit to the original author(s) and the source, provide a link to the Creative Commons license, and indicate if changes were made. 


\section{INTRODUCTION}

Emerging viral diseases are considered as major public health threat to humans and wildlife. Over the past several decades, scientists have been studying viruses to better understand the ways to prevent the rapid spread of diseases during an outbreak. Viruses are likely the most abundant organisms on the earth, and they are not absolutely alive. Viruses today are considered to be in the gray area between the living and non-living things and provoke our thoughts about these minute lifeforms as the precursors of life. Evolution of the global burden due to viral infections on the field medicine have been mostly transformed into a victory accompanied by unlocking the potential of knowledge and breakthrough technological advancements. Innovative contribution to immunization by Edward Jenner and subsequent eradication of small pox remains as the striking examples for the victory of mankind over the past epidemics and pandemics. These events not only inspire hope, but also remind us the plausibility of ending up historical pandemics and global threats. The current disastrous scenario and the real-world outbreak of Coronavirus poses complex challenges to the global public health, research and medical communities and ultimately to our existence. A successful prophylaxis is the need of the hour, yet the increasing prevalence and epidemiological reports have puzzled us with questions to be addressed instantly.

A new virus breaking out

A school of thought prevails about the origin of the viruses. When a piece of nucleic acid is shattered out of a cellular catastrophe or any such event, it retains its instinct to remain as the molecule of life allowing it to survive. Such a molecule covers itself up with a shield of amino acids and/or with lipids to enter and get integrated into a living cell. The cell that harbours such particle can ultimately become the viral host. The survival instinct imprinted in the nucleic acid of the particle can thrive the design and dimension of its cover with a choice for its cellular milieu. This features the virus and its shape that determine its specific host. Considering this hypothesis to be true, any piece of nucleic acid, the master biomolecule, can evolve as a potential infectious agent or a virus. The other factors that determine the host for such an evolving virus remains unexplored. In the light of this fact, the host and/or the conditions in which the virus had evolved must be understood for predicting the putative hosts for these evolving pathogenic viruses. The host immunity develops slowly to resist the virus in its due course. Such an event flings a pressure on the virus to have a new, better host for its survival and it happens to be newly emerging virus like SARS-CoV-2 with a new host and its pathogenicity leading to a pandemic. Coronaviridae

Coronaviridae is a large family of viruses that are phylogenetically distant and infects a broad range of hosts. The data on these viruses as the etiology resolved the long-mysterious diseases like infectious bronchitis in birds (Mcintosh, 1974). The members of this family includes positive stranded RNA viruses that are known for replication within the cytoplasm. The diversity of these viruses are defined by the viral quasispecies (Domingo et al., 2012). The viruses having such large diversity are difficult to be fathomed and the outbreaks caused by these viral pathogens create a paucity of knowledge. Hence, eradication of disease cause by viruses like CoVID-19 requires a novel strategy that integrates both knowledge and technology.

\section{Cross species transmission}

A wide range of animal species have been documented as a natural host for the members of Coronaviridae (Chan and Chan, 2013). Even after the establishment of successful host, these viruses crave for many other intracellular niches for a better cellular milieu. The host species that contracted the virus can enthral the virus by developing immunity against it. This prevents the autonomy of the viral life cycle as the host immunity would have co-evolved to resist the virus. It flings a selection pressure on the viral pathogen to jump into a new host-species across a taxonomic and geographical barrier. In addition to this, other physiochemical factors also need to be adapted by the virus. The animal viruses usually have a specific structure on cell surface that plays a crucial role for their attachment on the host cells followed by their entry into host cells. The outer envelope of Coronaviridae members bears club-shaped spikes that are widely spaced on the surface giving them a crown like appearance. This 
spatial arrangement of the spike on viral surface can offer adaptability for the virus to evolve more rapidly and successfully. This feature can add risk that follow the current pandemic as the coronaviruses are capable of such cross-species transfer. In other words, this pandemic can be infectious to threaten the life of any species on the planet for it requires any other living system to survive. Such extension of the host range by Murine Coronavirus to exploit the cells to express a receptor has been experimentally demonstrated (Schickli et al., 1997). Existing evidences and experiences with HIV origin in chimpanzees and its spread in the humans are excellent examples for such cross species transmission (Gao et al.,1999). This kind of transfer are easier for Coronaviridae members as they are already having arthropods and other phylogenetically distant species as their hosts (Cavanagh, 2005; Granzow, 2003). The wisdom for analysing the frequency and chances of this event is dearth. This concern encases not only the mankind but includes every other biotic components of the nature that are vulnerable to be killed by the viruses.

RNA as genetic material

Possession of RNA as its genetic material serves as an advantage for the evolution of the many viruses. The RNA is known for its instability. As a result, the RNA as genetic material is readily mutable and serve as the primary tool for evolving etiological agents of emerging diseases (Holmes, 2009). Every mutation resulting in nucleotide sequence change can have drastic effects even if it is a silent mutation. However, the occurrence of spontaneous mutation and their rates can be experimentally studied using invitro and in vivo models (Halligan and Keightley, 2009). The plausibility of recombination in the RNA genome is greater and it occurs due to the evolutionary pressure on the virus by rendering a survival advantage for the viruses (Simon-Loriere and Holmes, 2011; Worobey and Holmes, 1999). The need

Every one of us was born with immune system that acts like a security. The viral pathogens are naturally eliminated by our immune system through production of monoclonal antibodies (magic bullets) against a specific pathogen. These magic bullets are usually custom-made with high specificity by the immune system in response to a specific pathogen. Such neutralizing monoclonal antibodies must be available by from individuals who had survived the CoVID-19 infection (Winter and Milstein, 1991). Such antibodies have to be identified and can be used for passive immunization. Alternatively, these antibodies can be engineered to produce chimera or intrabodies to target intracellular antigens to interfere with the viral replication as an effective therapeutic strategy (Kontermann, 2004). Further, antibody engineering can improve the sensitivity of the diagnosis of viral pathogens that easily evade the innate barriers and antiviral senses like interferon (Zhang and Yoo, 2016). In such manner, the need of the time must be addressed by integration of every arena of research to combat the COVID-19 pandemic threat (Kumar et al., 2020). This need of the hour is the onus on every clinical researcher till achieving the remedy for the prevailing scenario of the widespread pandemic that is now threatening all of humankind. The pandemic invokes us to utilize the associated risk as an opportunity to integrate the knowledge, technology and every other prowess for identifying an absolute prophylaxis for our survival.

\section{ACKNOWLEDGMENTS \\ None.}

\section{CONFLICT OF INTEREST}

The listed author(s) declare no conflict of interest in any capacity, including competing or financial.

\section{AUTHORS' CONTRIBUTION}

All listed author(s) have made a substantial, direct and intellectual contribution to the work, and approved it for publication.

\section{FUNDING}

None.

\section{ETHICS STATEMENT}

This article does not contain any studies with human participants or animals performed by any of the authors.

\section{AVAILABILITY OF DATA}

Not applicable. 


\section{REFERENCES}

1. Cavanagh D. Coronaviruses in poultry and other birds. Avian Pathol. 2005;34(6):439-448. https://doi. org $/ 10.1080 / 03079450500367682$

2. Chan, P.K. and Chan, M.C. Tracing the SARS-coronavirus. $J$ Thorac Dis. 2013;5:S118.

3. Domingo E, Sheldon J, Perales C. Viral quasi species evolution. Microbiol. Mol. Biol. Rev. 2012;76(2):159216. https://doi.org/10.1128/MMBR.05023-11

4. Gao F, Bailes E, Robertson DL, et al. Origin of HIV-1 in the chimpanzee Pan troglodytes troglodytes. Nature. 1999;397(6718):436-441. https://doi. org/10.1038/17130

5. Granzow H. Detection and ultrastructural characterization of a novel virus from cyprinids. Microsc. Microanal. 2003;9(S03):514-514. https://doi. org/10.1017/S1431927603041023

6. Halligan DL, Keightley PD. Spontaneous mutation accumulation studies in evolutionary genetics. Annu Rev Ecol Evol Syst. 2009;40:151-172. https://doi. org/10.1146/annurev.ecolsys.39.110707.173437

7. Holmes EC. The evolutionary genetics of emerging viruses. Annu. Rev. Ecol. Evol. Syst. 2009;40:353372. https://doi.org/10.1146/annurev. ecolsys.110308.120248

8. Kontermann RE. Intrabodies as Therapeutic Agents Methods. 2004;34(2):163-170. https://doi. org/10.1016/j.ymeth.2004.04.002

9. Kumar S, Rathi B. Coronavirus Disease COVID-19:
A New Threat to Public Health. Current topics in Medicinal Chemistry, 2020. https://doi.org/10.2174/ 1568026620999200305144319

10. Mclntosh K. Coronaviruses: A comparative review. In Current Topics in Microbiology and Immunology/Ergebnisse der Mikrobiologie und Immunitatsforschung, 1974;85-129. Springer, Berlin, Heidelberg. https://doi.org/10.1007/978-3-64265775-7_3

11. Schickli JH, Zelus BD, Wentworth DE, Sawicki SG, Holmes KV. The murine coronavirus mouse hepatitis virus strain A59 from persistently infected murine cells exhibits an extended host range. J Virol. 1997;71(12):9499-9507. https://doi.org/10.1128/ JVI.71.12.9499-9507.1997

12. Simon-Loriere E, Holmes EC. Why do RNA viruses recombine?. Nature Rev Microbiol. 2011;9(8):617-626. https://doi.org/10.1038/nrmicro2614

13. Winter $\mathrm{G}$ and Milstein $\mathrm{C}$. Man-made antibodies. Nature. 1991;349(6307):293-299. https://doi. org/10.1038/349293a0

14. Worobey $M$, Holmes EC. Evolutionary aspects of recombination in RNA viruses. J Gen Virol. 1999;80(10):2535-2543. https://doi. org/10.1099/0022-1317-80-10-2535

15. Zhang $Q$, Yoo D. Immune evasion of porcine enteric coronaviruses and viral modulation of antiviral innate signaling. Virus Res. 2016;226:128-141. https://doi. org/10.1016/j.virusres.2016.05.015 